\title{
Metacontingências de Autocontrole Ético: Efeitos do Aumento da Magnitude de Reforço ${ }^{1}$
}

\author{
Holga Cristina da Rocha Gomes ${ }^{2}$ \\ Faculdade Pitágoras \\ Emmanuel Zagury Tourinho \\ Universidade Federal do Pará
}

\begin{abstract}
RESUMO - Este trabalho objetivou avaliar os efeitos da progressão da magnitude da consequência individual concorrente com a consequência cultural sobre a recorrência de um entrelaçamento previamente selecionado por consequências culturais em um arranjo de metacontingências de autocontrole ético. Estudantes universitários compuseram duas microculturas de laboratório, as quais foram expostas a um delineamento $\mathrm{ABACDC}$, em que, nas condições $\mathrm{A}$ e $\mathrm{B}$, havia concorrência entre metacontingências e contingências operantes e, nas condições $\mathrm{C}$ e D, tal concorrência foi suspensa. Adicionalmente, houve progressão da magnitude da consequência individual para as respostas impulsivas (que beneficiam apenas o indivíduo) nas condições B e D. Os resultados indicaram seleção de práticas culturais de autocontrole ético tanto nas condições sem concorrência, quanto nas condições com concorrência.
\end{abstract}

Palavras-chaves: transmissão cultural, análise do comportamento, comportamento de escolha

\section{Metacontingencies of Ethical Self-control: Effects of Increase in the Magnitude of Reinforcement}

\begin{abstract}
This study aimed to evaluate the effects of progression of the magnitude of individual consequence concurrent with cultural consequence on the recurrence of an interlocking previously selected by cultural consequences in a metacontingency arrangement of ethical self-control. Undergraduate students were assigned to two laboratory microcultures, which were exposed to an ABACDC design. The conditions $\mathrm{A}$ and $\mathrm{B}$ have concurrence between metacontingencies and operant contingencies and in $\mathrm{C}$ and $\mathrm{D}$ conditions such concurrence was suspended. Additionally, there was progression of the magnitude of the individual consequence result of impulse responses (receiving individual) in $\mathrm{B}$ and $\mathrm{D}$ conditions. The data indicated selection of ethical self-control cultural practices in both conditions, no concurrence and concurrence.
\end{abstract}

Keywords: cultural transmission, behavior analysis, choice behavior

Uma cooperativa de pescadores pode explorar e comercializar os mariscos da região que habitam, produzindo resultados imediatos que lhe são favoráveis, como o lucro com a venda dos mesmos. No entanto, o consumo não sustentável desse recurso natural compromete a disponibilidade desses mariscos para as gerações seguintes. Frequentemente somos expostos a situações de escolha desse tipo, em que podemos produzir consequências reforçadoras individuais associadas a consequências menos favoráveis para o grupo ou produzir consequências mais favoráveis ao grupo associadas a consequências individuais menos favoráveis (por exemplo, de menor magnitude).

Situações que envolvem concorrência entre contingências culturais e individuais têm sido descritas na literatura a partir da noção de autocontrole/autogerenciamento ético (Borba et al., 2014; Del Prette \& Del Prette, 2010; Tourinho, 2006; Tourinho \& Vichi, 2012). O adjetivo ético ressalta que o responder de um indivíduo também produz consequências

1 Nota: O texto é resultado do trabalho de dissertação da primeira autora, sob orientação do segundo autor

2 Endereço para correspondência: Rua Retiro Natal, s/n, Condomínio Marfim 2, bloco 5, ap 103, Jardim Eldorado, São Luís, MA, Brasil. CEP: 65.067-283.E-mail: holga_c@yahoo.com.br para a cultura da qual participa e não apenas para si. Responder com autocontrole ético, então, significa responder de modo a produzir consequências favoráveis para a cultura em circunstâncias em que essa produção compromete (ou concorre com) a produção ou a magnitude de um efeito favorável apenas ao indivíduo (Borba et al., 2014; Tourinho \& Vichi, 2012).

Esse tipo específico de autocontrole tem sido alvo de algumas pesquisas experimentais sobre a seleção de unidades culturais (e.g., Borba, 2013; Borba et al., 2014; Magalhães, 2013; Ortu, Becker, Woelz, \& Glenn, 2012), com base no conceito de metacontingência (Glenn, 2004). Uma metacontingência descreve relações funcionais entre (a) contingências comportamentais entrelaçadas (CCEs), quando o comportamento de um indivíduo é parte do ambiente ao qual outro responde; (b) produtos agregados (PAs), efeitos resultantes da inter-relação do comportamento dos indivíduos; e (c) consequências culturais (CCs), mediadas por agentes externos ao entrelaçamento e que o selecionam juntamente com o seu produto agregado (cf. Glenn, 2004; Glenn \& Malott, 2004; Malott \& Glenn, 2006).

Pesquisas de seleção cultural que abordam a concorrência entre metacontingências e contingências operantes avaliam 
CCEs que produzem um dado PA e são selecionadas por uma $\mathrm{CC}$, em uma condição em que as respostas individuais requeridas para a produção do PA alvo geram, como consequências operantes, perda de reforçadores (Magalhães, 2013) ou reforçadores em menor magnitude (Borba, 2013; Ortu et al., 2012), concorrentemente a contingências individuais que poderiam gerar reforçadores imediatos de maior magnitude, mas comprometendo a produção da CC.

Ortu et al. (2012) realizaram um conjunto de experimentos baseados no jogo Dilema do Prisioneiro, com o objetivo de verificar o efeito da CC sobre a seleção de CCEs (XXXX ou YYYY). Um grupo de quatro participantes foi exposto a uma tarefa experimental com duas possibilidades de escolhas em esquemas concorrentes: escolher X (resposta cooperativa) ou Y (resposta competitiva). Após a liberação das consequências individuais (CIs), CCs eram liberadas (o feedback de mercado, dinheiro dividido entre os quatro participantes) contingentemente à produção do PA correspondente à condição experimental em vigor. $\mathrm{Na}$ condição XXXX, a escolha de $\mathrm{X}$ produzia um valor adicional para o grupo e escolhas Y não produziam nenhum valor adicional. $\mathrm{Na}$ condição YYYY, ocorria o inverso. Os dados mostraram que as CCs programadas foram efetivas em selecionar as coordenações XXXX e YYYY, mesmo gerando um ganho menor que responder competitivamente.

No preparo experimental utilizado por Ortu et al. (2012), havia concorrência entre contingências operantes e contingências culturais, sendo as CIs e CCs de mesma natureza, o que torna menos evidente a função diferenciada de cada uma. Borba (2013) também investigou a concorrência entre contingências individuais e culturais, porém com CCs (carimbos trocáveis por itens escolares a serem doados para escolas públicas) e CIs (fichas trocáveis por dinheiro) de naturezas diferentes. Além da mudança na natureza das consequências, nesse estudo havia a possibilidade de as CCs beneficiarem membros externos ao entrelaçamento (os alunos das escolas que receberiam os kits escolares), algo também usual em práticas culturais encontradas fora do laboratório. Adicionalmente, houve substituição de participantes, caracterizando mudança geracional. A concorrência entre contingência operante e metacontingência foi programada de modo que a magnitude da CI era maior quando a resposta era impulsiva (não compatível com o entrelaçamento alvo) e menor quando autocontrolada (requerida para a produção do PA).

A tarefa dos participantes no estudo de Borba (2013) foi igual à utilizada no presente estudo (escolher linhas em uma matriz 10x10). A CI de maior magnitude (três fichas) era apresentada contingentemente às escolhas de linhas ímpares (respostas impulsivas), enquanto a CI de menor magnitude (uma ficha) era contingente às escolhas de linhas pares (respostas autocontroladas). A CC era produzida se todos os participantes selecionassem linhas pares de cores diferentes. Desse modo, cada participante poderia produzir uma ficha (CI) para si e, em conjunto, três itens escolares (CC). Os resultados demonstraram que a CC programada selecionou o entrelaçamento alvo e seus PAs, mesmo com a produção de CIs de menor magnitude.

Nos experimentos de Borba (2013), não havia incompatibilidade entre as CIs e culturais, ou seja, os participantes poderiam produzir ambas se respondessem em coordenação. A diferença estava na magnitude da consequência individual. Em um estudo com delineamento diferente, Magalhães (2013) buscou investigar se ocorreria seleção de CCEs e seus PAs se, para tanto, fosse necessário deixar de produzir CIs e perdê-las. Nesse estudo a tarefa consistia do preenchimento de números em uma tela de computador. CIs eram contingentes à relação entre os números gerados pelo computador e os números inseridos pelo participante. $\mathrm{CCs}$ eram contingentes às relações entre as somas dos números inseridos por cada participante. A autora realizou quatro experimentos, que também envolveram mudança de geração e CIs (pontos trocáveis por dinheiro) e CCs (bônus trocáveis por itens escolares a serem doados para uma instituição de caridade) de naturezas diferentes. Os resultados demonstraram que houve seleção cultural apenas em algumas gerações, sem transmissão de forma consistente.

O estudo de Magalhães (2013) e mais consistentemente o estudo de Borba (2013) demonstraram que o autocontrole ético, enquanto prática cultural, pode ser selecionado por consequências culturais, mesmo quando a produção dessas últimas compromete ganhos individuais. Borba (2013) utilizou, ao longo dos experimentos, CIs de baixa magnitude e com valores muito próximos (uma ficha para a resposta autocontrolada e três para a impulsiva), sendo que essa diferença de magnitude permanecia constante ao longo do experimento. Já Magalhães (2013) programou contingências individuais aversivas para alguns dos participantes (deixar de produzir CIs e perdê-las). Uma questão não avaliada nesses estudos diz respeito a circunstâncias em que ocorre variação na magnitude da CI após a seleção do entrelaçamento.

Embora sejam ainda escassos os dados sobre seleção cultural em condições de concorrência entre metacontingências e contingências operantes, o estudo de Ortu et al. (2012) sugeriu que é provável que a efetividade da CC, nessas circunstâncias, dependa parcialmente da relação entre magnitudes da CC e da CI. Tal relação certamente é mais saliente e/ou relevante quando CC e CI têm a mesma natureza (como naquele estudo), mas algo semelhante pode também ocorrer quando CC e CI têm naturezas distintas. Variações na magnitude da CI após seleção de CCEs concorrentes podem eventualmente afetar a manutenção das últimas, assim como também é possível que as interações verbais intragrupo exerçam alguma função para a manutenção do entrelaçamento nessas circunstâncias.

No presente trabalho, pretendeu-se avaliar o efeito do aumento progressivo da magnitude da CI sobre a manutenção de um entrelaçamento por CCs, após processo de seleção por metacontingência, em uma condição de concorrência entre metacontingência e contingência operante. Identificar variáveis relevantes para a manutenção do entrelaçamento nessas condições pode contribuir para a elaboração de tecnologias comportamentais que aumentem a probabilidade de emissão de comportamentos de autocontrole ético que promovam a sobrevivência das culturas. A magnitude do reforço neste estudo, como no de Borba (2013), correspondeu à quantidade de fichas trocáveis por dinheiro que cada participante podia produzir. 


\section{Método}

\section{Participantes}

Participaram deste estudo 41 alunos de graduação, de ambos os sexos, com idades entre 18 e 47 anos, de diversos cursos (com exceção de Psicologia) de uma universidade pública. Desses, 20 participaram da primeira microcultura (MC1) e 21, da segunda (MC2). Os participantes foram recrutados em seus locais de aulas e aqueles que aceitaram participar foram conduzidos à sala de espera do laboratório, onde foram esclarecidos sobre a pesquisa e assinaram o Termo de Consentimento Livre e Esclarecido. Os participantes foram alocados em um grupo de três membros e, a cada vinte ciclos, o participante mais antigo foi substituído (com exceção das condições B e D). Cada posição no grupo correspondia a uma linhagem (LA, LB e LC), que contou com sucessivos participantes ao longo do experimento. As duas microculturas foram expostas às mesmas condições experimentais.

\section{Ambiente Experimental e Materiais}

O estudo foi conduzido em uma sala experimental com dois ambientes, separados por um espelho unidirecional: (a) uma sala de coleta de dados e (b) uma sala de observação e controle dos equipamentos. O material incluiu mobiliário (mesas, cadeiras, armários), equipamentos eletrônicos (filmadora com tripé para registro das sessões, computador conectado à TV de LCD de 42 polegadas onde foi projetada a matriz descrita adiante e notebook para registro das respostas dos participantes em uma planilha em Microsoft Excel), instruções impressas para os participantes, fichas plásticas em forma de moedas, tigelas plásticas para as fichas, carimbo de uma carinha feliz, uma folha para o registro dos carimbos, itens escolares para compor kits (lápis preto, lápis de cor, borrachas, apontadores, caderno, tesoura, régua etc.) e alimentos diversos (para consumo dos participantes durante as sessões).

\section{Procedimento}

A tarefa geral. A tarefa das microculturas consistia de escolher linhas em uma matriz de 10 linhas e 10 colunas projetada na TV LCD. As linhas e colunas eram sinalizadas, respectivamente, com números e letras. As linhas da matriz tinham cinco cores diferentes alternadas (cada cor em uma linha par e uma linha ímpar). Na intersecção de cada linha com cada coluna, havia um círculo preenchido ou um círculo sem preenchimento (Figura 1).

Após o experimentador solicitar, cada participante escolhia (um por vez) uma linha da matriz, informando-a em voz alta. As escolhas dos três participantes correspondem a um ciclo que compreendia as seguintes etapas: (a) solicitação do experimentador para que um membro do grupo escolhesse uma linha; (b) a escolha de uma linha por um membro do grupo; (c) a informação de uma coluna pelo

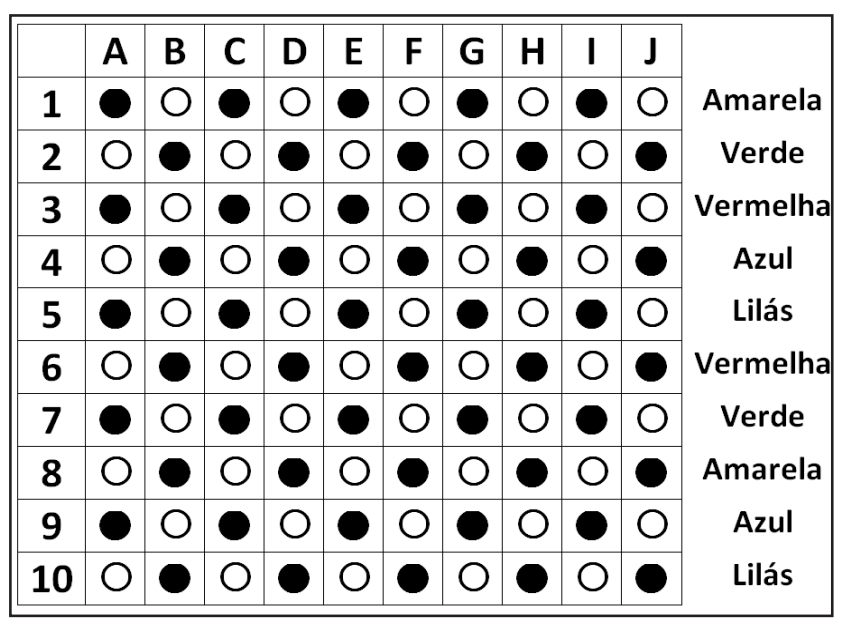

Figura 1. Matriz empregada no estudo e as respectivas cores de cada linha

experimentador, de acordo com a escolha do participante e com as contingências programadas; (d) quando na interseção da linha escolhida pelo participante com a coluna escolhida pelo experimentador havia um círculo preenchido, o participante recebia a CI de maior magnitude; quando havia um círculo vazio, o participante recebia uma CI de menor magnitude (esse evento constituía a consequência operante); (e) repetição das etapas "a" a "d" para os demais participantes do grupo; e (f) a informação do experimentador sobre o sucesso ou insucesso do grupo em produzir um carimbo e a colocação do carimbo na folha de controle dos kits escolares, quando era o caso (esse evento constituía a consequência cultural). A cada ciclo, a ordem de escolha dos participantes era alterada e não havia restrição quanto a selecionar a mesma linha escolhida por outro participante.

Contingências operantes e metacontingências. $O$ experimento previa, em algumas condições (A e B), uma situação de concorrência entre contingências operantes e metacontingências, sob as quais poderiam ser produzidas CIs de maior magnitude, ou CIs de menor magnitude associadas a CCs, quando houvesse coordenação entre as escolhas dos participantes. Nas outras condições (C e D), essa concorrência estava suspensa.

A CI de maior magnitude (inicialmente três pontos) era contingente à escolha de uma linha ímpar e era depositada em uma tigela plástica à frente do participante, imediatamente após a sua escolha individual. Em algumas fases do estudo (B e D), a CI contingente à seleção de linhas ímpares teve sua magnitude aumentada progressivamente. Escolhas de linhas pares produziam CIs de menor magnitude (sempre um ponto), também depositada em uma tigela plástica à frente do participante, imediatamente após a sua escolha. Nas condições de concorrência entre metacontingência e contingência operante, respostas em linhas ímpares eram consideradas impulsivas, enquanto escolhas de linhas pares eram consideradas autocontroladas.

A CC (um item escolar) era contingente à escolha, pelos membros do grupo, de linhas pares de cores diferentes (PA). Portanto, para que o PA e consequentemente a CC fossem produzidos, era necessário que todos os participantes respondessem produzindo reforçadores individuais de menor magnitude, caracterizando uma instância de autocontrole 
ético. Nas condições em que a concorrência esteve suspensa, a CC (explicada adiante) foi contingente a escolhas de linhas de cores diferentes, independentemente de serem pares ou ímpares.

As CIs eram representadas por fichas coloridas, trocáveis por dinheiro ao final da participação no estudo. Em função da possibilidade de aumento progressivo da magnitude da CI, essas fichas foram organizadas por pontuação (como fichas de pôquer) em um dispositivo com seis divisórias que ficava sobre a mesa de coleta, acessível à visualização pelos participantes. Em cada divisória, foram colocadas fichas de cores diferentes, sendo que cada cor correspondia a uma pontuação: 1, 3, 5, 10, 20 e 30 pontos. Cada ponto equivalia a $\mathrm{R} \$ 0,05$. A consequência cultural era um carimbo de uma carinha feliz em uma folha de controle, trocável por itens escolares. Ao final do experimento os carimbos eram trocados por itens escolares para doação a uma escola pública. Ao longo do experimento, os itens para o kit escolar ficavam sobre uma bancada na sala experimental, visíveis aos participantes. Cada participante foi informado de que poderia participar da sessão de doação dos itens escolares, se assim desejasse. Após o estudo, os participantes foram informados da data e local da doação dos itens.

Delineamento experimental. As duas microculturas foram expostas ao mesmo delineamento experimental (ABACDC), com o objetivo de observar a generalidade dos dados. Cada microcultura era composta por três participantes e, em algumas condições, a cada vinte ciclos, um membro era substituído.

Nas condições A e B, havia a concorrência já descrita entre metacontingências e contingências individuais. A primeira condição A foi iniciada com a leitura da primeira instrução. O critério para a mudança de condição era a produção da CC em $80 \%$ dos últimos 50 ciclos (três gerações sucessivas) ou a ocorrência de 100 ciclos. Atingido o critério, mudava-se imediatamente para a condição B, com o fornecimento da segunda instrução. Nessa condição, foi programado aumento progressivo da magnitude da CI para escolhas de linhas ímpares (respostas impulsivas) ao longo dos ciclos. A cada cinco ciclos, ocorria a adição de dois a cinco pontos, de forma randômica, sobre a magnitude da CI.

Portanto, na condição B, a escolha de linhas ímpares produzia uma quantidade progressivamente maior de pontos. A condição iniciava com uma fase (B1) em que a resposta impulsiva produzia os três pontos da condição anterior mais o aumento (de dois a cinco pontos). Após cinco ciclos, a mesma resposta produzia a quantidade de pontos da fase B1 mais um novo aumento variável de dois a cinco pontos (fase B2). Após mais cinco ciclos, a resposta impulsiva produzia a quantidade de pontos da fase B2 mais um novo aumento (fase B3) e assim por diante até que a proporção de respostas impulsivas atingisse $80 \%$ dos últimos 50 ciclos ou fossem completados 100 ciclos. Escolhas de linhas pares continuavam produzindo apenas uma ficha ao longo de toda a condição. Imediatamente após, havia um retorno à condição $\mathrm{A}$, seguida pela condição $\mathrm{C}$, pela condição $\mathrm{D}$ e retorno a condição $\mathrm{C}$.

As condições $\mathrm{C}$ e $\mathrm{D}$ eram semelhantes às condições $\mathrm{A}$ e $\mathrm{B}$, respectivamente. A diferença era que a concorrência entre metacontingências e contingências operantes estava suspensa naquelas condições. Assim, escolhas de linhas de cores diferentes, fossem elas ímpares ou pares, produziam o item escolar. A mudança de condição ocorria quando a produção da CC alcançava $80 \%$ dos últimos 50 ciclos ou ao final de 100 ciclos.

Nas condições $\mathrm{A}$ e $\mathrm{C}$, a cada 20 ciclos de exposição às metacontingências, o participante mais antigo era substituído por um novo participante, o que constituía uma mudança de geração. Nas condições de aumento progressivo da CI (B e D), não havia essa substituição, sendo que os sujeitos que ingressaram nessas condições deveriam participar, por 10 ciclos, das condições imediatamente anterior e posterior, de modo que pudessem ser expostos às mudanças das condições. Durante as mudanças de gerações, os participantes mais antigos instruíam os mais novos.

Instruções. Ao início do experimento, foi fornecida a seguinte instrução: "Vocês participarão de um estudo sobre comportamento de escolha. A tarefa de vocês será escolher, um de cada vez, uma linha na matriz que se encontra exposta nessa TV [apontava a TV]. Cada um deverá informar, em voz alta, a linha escolhida, falando o número da mesma. Depois de realizada tal escolha, o computador irá selecionar, através de um sistema pré-definido uma coluna para aquela jogada. $\mathrm{Na}$ interseção entre a linha escolhida por você e a coluna escolhida pelo computador, pode haver um círculo preenchido ou vazio. Dependendo de qual símbolo for gerado, você poderá ganhar um ou mais pontos, que serão depositados nesses recipientes à frente de vocês [apontava os recipientes] na forma de fichas. Ao final da participação, cada um de vocês poderá trocar cada ponto por cinco centavos. Em determinados momentos, vocês poderão ganhar, além das fichas, itens escolares que serão doados a uma escola pública. Esses itens são representados por carimbos nessa folha que tenho à minha frente [mostrava a folha], e cada carimbo equivale a um item escolar. Lembrem-se de que as fichas produzidas e depositadas nos recipientes plásticos serão trocadas por dinheiro, que será pago a cada um de vocês individualmente ao final de sua participação no estudo e que os carimbos são trocáveis por itens escolares a serem doados para uma escola pública. Ao fim da sessão, agendaremos o dia para a entrega do kit escolar e vocês poderão participar dessa entrega, se assim desejarem. Vocês podem usar as folhas à sua frente para fazer anotações e conversar livremente entre vocês". Instrução mínima para o início da condição B: "A partir desse momento, vocês poderão ganhar um número diferente de pontos".

\section{Resultados}

A Figura 2 apresenta as frequências acumuladas de escolhas de linhas ímpares e de recorrência de CCEs e seus PAs, bem como a porcentagem de produção de CCs nos últimos 50 ciclos de cada condição para ambas as microculturas.

A Microcultura 1 (MC1) durou 512 ciclos. A primeira condição A foi encerrada pelo número máximo de ciclos (100 ciclos). Observa-se, na Figura 2, que, nos primeiros 40 ciclos, não houve produção do PA. Destaca-se a predominância de escolhas de linhas ímpares até por volta do ciclo 70, quando há o aumento de seleção de linhas pares, o que coincide 


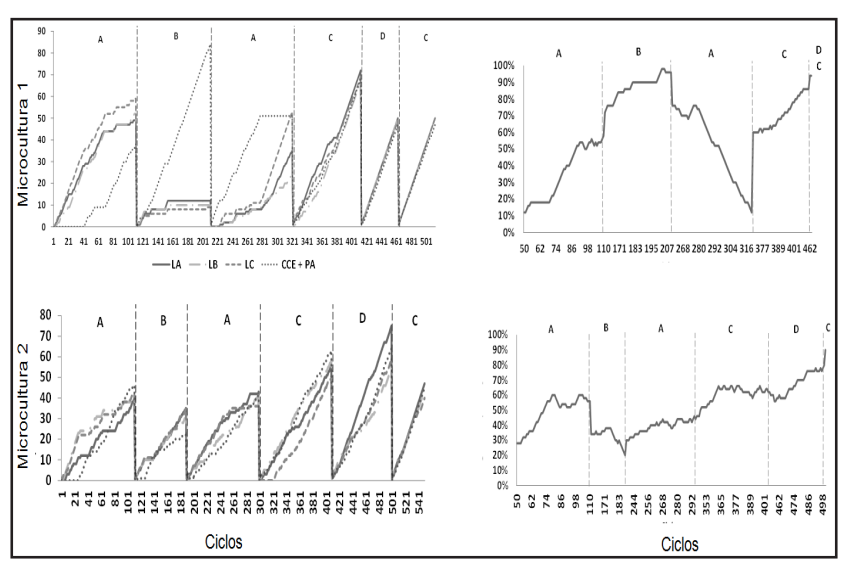

Figura 2. O painel superior apresenta as frequências acumuladas de escolhas de linhas ímpares e de CCEs + PAs na Microcultura 1 , a esquerda, e a porcentagem de produção da $\mathrm{CC}$ nos últimos 50 ciclos, a direita. $\mathrm{O}$ painel inferior apresenta esses dados para a Microcultura 2.

Nota. Cada posição no grupo corresponde a uma linhagem (LA, LB e LC).

com o aumento da taxa de recorrência de CCEs e seus PAs. Embora o grupo não tenha alcançado $80 \%$ de recorrência do entrelaçamento alvo ao longo de 50 ciclos nessa condição, essa taxa alcançou $50 \%$ nos últimos 10 ciclos. Os últimos participantes permaneceram por mais 10 ciclos nessa condição e foram expostos à condição seguinte de aumento progressivo da CI, quando não haveria mudança de geração.

A condição $\mathrm{B}$, de concorrência e com aumento progressivo da CI, começou no ciclo 111. Nota-se, na Figura 2, que houve seleção cultural, sendo que esta foi a condição com maior taxa de produção do PA, observada em 84 dos 100 ciclos. Essa etapa também foi encerrada pelo número máximo de ciclos, visto que o critério de desempenho era $80 \%$ de respostas impulsivas nos últimos 50 ciclos e, mesmo com o aumento progressivo da CI, os participantes responderam de modo autocontrolado, atingindo $90 \%$ de produção da CC nos últimos 10 ciclos. Mesmo com a alta taxa de respostas autocontroladas, eventualmente um participante escolhia uma linha ímpar, de modo que o grupo pôde entrar em contato com o aumento da magnitude da CI. No ciclo 151, por exemplo, o P6MC1 (os participantes são aqui identificados com $\mathrm{P}$, seguido da ordem em que o participante ingressou na coleta e da microcultura da qual ele fez parte) escolheu uma linha ímpar, produzindo 31 pontos; no ciclo 206, o mesmo participante voltou a responder de modo impulsivo, produzindo 72 pontos. Nas duas ocasiões, os participantes voltaram a escolher linhas pares nos ciclos seguintes.

O retorno à condição $\mathrm{A}$ iniciou-se no ciclo 211 e também foi encerrada pelo número máximo de ciclos. Nos primeiros 10 ciclos, em que foram mantidos os mesmos participantes da condição anterior, o PA foi produzido em todas as oportunidades. No entanto, a produção agregada caiu ao longo da mudança de gerações, não ocorrendo mais nenhuma produção por 43 ciclos consecutivos (a partir do ciclo 278, até o fim da condição). Note-se que o último participante remanescente da condição anterior foi substituído no ciclo 271. Nessa condição, houve seleção de escolhas de linhas pares até por volta do ciclo 280, quando houve aumento da frequência de escolhas de linhas ímpares.

A condição $\mathrm{C}$, quando a concorrência foi suspensa, iniciou no ciclo 321 e encerrou-se no ciclo 412 . O critério de $80 \%$ de produção da CC foi alcançado no ciclo 402. Como houve uma mudança de geração no ciclo imediatamente anterior, essa condição foi mantida por mais 10 ciclos, critério para os participantes ingressarem na condição seguinte de aumento progressivo da CI. Também houve seleção operante de escolha de linhas ímpares.

A condição $\mathrm{D}$, sem concorrência e com aumento progressivo da CI, foi iniciada no ciclo 413 e durou o número mínimo de 50 ciclos quando a produção da CC era de $94 \%$. $\mathrm{O}$ mesmo ocorreu com o retorno à condição $\mathrm{C}$, que se iniciou no ciclo 463. Nessas duas condições, a produção da CC foi observada desde o primeiro momento e a recorrência das CCEs+PAs manteve-se em altas taxas ao longo de todos os ciclos. Em ambas as condições, houve também seleção operante de escolhas de linhas ímpares, sendo que houve apenas uma ocorrência de seleção de linha par na condição $\mathrm{D}$ e, no retorno à condição $\mathrm{C}$, todas as escolhas foram de linhas ímpares.

A Microcultura 2 (MC2) durou 549 ciclos. Embora com mais ciclos que a $\mathrm{MC1}$, na $\mathrm{MC} 2$, houve 281 ocorrências do $\mathrm{PA}$, enquanto naquela foram produzidos $335 \mathrm{PAs}$. A primeira condição A foi encerrada pelo número máximo de ciclos (100 ciclos). Diferentemente da MC1, a primeira ocorrência do entrelaçamento alvo aconteceu mais cedo, no ciclo 26 . A partir do ciclo 72 , a porcentagem de produção da $\mathrm{CC}$ oscilava entre $50 \%$ e $60 \%$ nos últimos 50 ciclos. Do início da sessão até por volta do ciclo 30 , predominaram escolhas de linhas ímpares. A partir daí, passou a ocorrer maior taxa de linhas pares. Os últimos três participantes permaneceram por mais 10 ciclos nessa condição antes de passarem para a condição seguinte.

A Figura 2 evidencia que a porcentagem de produção da $\mathrm{CC}$ alcançada na condição anterior não se manteve na condição $\mathrm{B}$, de concorrência e aumento progressivo da CI. Essa condição começou no ciclo 111 e foi encerrada no ciclo 188 , quando foi alcançado o critério de $80 \%$ de respostas impulsivas nos últimos 50 ciclos, ou seja, $20 \%$ de respostas autocontroladas. Nesse momento, a magnitude da CI para respostas impulsivas era de 22 pontos. A diferença entre frequência acumulada de escolhas de linhas ímpares e pares foi baixa, 101 e 133 respectivamente.

O retorno à condição A iniciou no ciclo 189 , sendo esta encerrada pelo número máximo de ciclos. Nos primeiros 10 ciclos em que foram mantidos os mesmos participantes da condição anterior, o PA foi gerado apenas uma vez. A partir da terceira mudança de geração, quando os três participantes da condição anterior já haviam sido substituídos, houve aumento consistente da ocorrência de CCEs e seus PAs, atingindo 50\% de produção nos últimos 10 ciclos. No início da condição, predominava o padrão de escolha de linhas ímpares, esse padrão se alterou para escolhas de linhas pares na segunda metade da condição.

Quanto às condições de suspensão da concorrência, a primeira condição C foi iniciada no ciclo 299 e encerrada no ciclo 408 pelo critério de número máximo de ciclos. Mesmo não alcançado o critério de encerramento de condição, a taxa 
de recorrência do PA nos últimos 10 ciclos chegou a $60 \%$. Também se observou dispersão do padrão de escolha de linhas ao longo da condição, com frequências acumuladas de escolha de linhas ímpares (162), muito próximo da frequência acumulada de linhas pares (168). Os participantes foram mantidos por mais 10 ciclos, sendo os mesmos que ingressaram na condição seguinte.

A condição $\mathrm{D}$, de aumento progressivo da $\mathrm{CI}$, iniciou no ciclo 409 e durou 91 ciclos, quando foi alcançado o critério de $80 \%$ de produção do PA nos últimos 50 ciclos. Além de seleção cultural, também houve seleção operante, com alta frequência de escolha de linhas ímpares.

O retorno à condição $\mathrm{C}$ foi iniciado no ciclo 499 e durou o mínimo de ciclos requerido (50). A produção agregada nesse momento era de $90 \%$. A maioria das escolhas dos participantes concentrou-se em linhas ímpares (com apenas 19 escolhas de linhas pares em toda a condição), demonstrando a seleção operante dessa classe de resposta.

Após a visualização da gravação do experimento, foi possível observar algumas interações verbais que podem contribuir para entender os resultados aqui obtidos. Entre essas interações, destacam-se algumas que ocorreram na condição B da $\mathrm{MC1}$ (ver Tabela 1).

Já na condição $\mathrm{B}$ da $\mathrm{MC} 2$ quando o $\mathrm{P} 8 \mathrm{MC} 2$ sugeriu aos demais membros do grupo que eles deveriam tentar em uma rodada ganhar os pontos e, em outra, o item escolar, a P6MC2 respondeu que os itens escolares já estavam comprados, então os experimentadores iriam doar de qualquer jeito.

\section{Discussão}

Os resultados deste estudo são consistentes com os de outras pesquisas experimentais (e.g., Cavalcanti et al., 2014; Magalhães, 2013; Pavanelli et al., 2014; Soares et al., 2012) em que a CC de natureza diferente da CI foi efetiva na seleção e manutenção de CCEs e seus PAs. Tal seleção ocorreu tanto nas condições sem concorrência entre contingências operantes e culturais, quanto nas condições com concorrência, porém a taxa de recorrência do entrelaçamento alvo e seus PAs foi diferente entre essas duas condições, como será discutido a seguir.

A ocorrência do entrelaçamento alvo nas condições sem concorrência parece ter ocorrido de forma mais consistente, visto que quase todas as condições, com exceção da primeira condição $\mathrm{C}$ da $\mathrm{MC} 2$, foram encerradas pelo critério de produção agregada, o que não ocorreu nas condições com concorrência. Naquelas condições, além de seleção cultural, houve transmissão da prática, sendo mantido o entrelaçamento alvo ao longo das gerações.

Nas condições em que houve concorrência entre metacontingência e contingência operante, o evento cultural foi menos efetivo na seleção e manutenção de CCEs+PAs, ainda que a taxa de recorrência desses tenha ficado sempre acima do acaso. $\mathrm{O}$ arranjo experimental empregado possibilitava 480 combinações de três cores diferentes e apenas 60 combinações de linhas pares de cores diferentes, de modo que a probabilidade de ocorrência do entrelaçamento alvo ao acaso era de $12,5 \%$. Na primeira condição $\mathrm{A}$, na condição $\mathrm{B}$ da $\mathrm{MC} 1$ e nas duas condições $\mathrm{A}$ da $\mathrm{MC} 2$, o

Tabela 1. Interações verbais entre os participantes da condição B da Microcultura 1 .

\begin{tabular}{|c|c|c|}
\hline Antecedente & Interações verbais & Efeito sobre as escolhas \\
\hline $\begin{array}{l}\text { No ciclo 132, após a P7MC1 } \\
\text { escolher por dois ciclos } \\
\text { linhas ímpares. }\end{array}$ & $\begin{array}{l}\text { P8MC1: "Vocês estão atrás da premiação máxima ou do item } \\
\text { escolar? (...) Então beleza, se a gente já tem os destinos da } \\
\text { premiação, a gente joga só por um ou a gente joga só por outro. Ou } \\
\text { vocês querem jogar nos dois lado?" } \\
\text { P6MC1 responde: "A gente pode balancear". } \\
\text { P8MC1: "A gente tem esses dois tipos de consequência: individual } \\
\text { e social. De uma forma ou de outra a gente é recompensado } \\
\text { das duas formas. Uma recompensa espiritual, coletiva e outra } \\
\text { individual". } \\
\text { P6MC1: "Eu prefiro a coletiva, porque eu já aprendi: é melhor doar } \\
\text { do que ser roubado". } \\
\text { P8MC1 pega as fichas nas mãos e diz: "Com essa quantidade de } \\
\text { dinheiro, a gente já tem o dinheiro suficiente pra voltar pra casa". }\end{array}$ & $\begin{array}{l}\text { Os participantes responderam } \\
\text { com autocontrole ético até o } \\
\text { ciclo } 149 .\end{array}$ \\
\hline $\begin{array}{l}\text { No ciclo } 150 \text { a P7MC1 } \\
\text { escolhe uma linha ímpar e } \\
\text { produz } 29 \text { pontos. Seguem- } \\
\text { se escolhas ímpares por mais } \\
\text { três ciclos. }\end{array}$ & $\begin{array}{l}\text { P8MC1: "A gente pode gerar o item escolar e ganhar moeda. E aí? } \\
\text { A gente tá a quatro vezes sem gerar o item escolar". } \\
\text { P6MC1: "É. Pode ser um item escolar agora". } \\
\text { P8MC1: "E você, P7MC1, o que tu achas?”. } \\
\text { P7MC1: "Ah, vocês decidem”. } \\
\text { P8MC1: "Não, é sério! Pode ser sincera. Tem dois tipos de } \\
\text { premiação: uma ganha mais moedas e outra ganha menos moedas. } \\
\text { A que ganha mais moedas não gera item escolar. Eu ainda } \\
\text { supostamente voto pelo item escolar". } \\
\text { P6MC1: "Então vamos produzir, né?!". } \\
\text { P8MC1: "Então vamos continuar"” }\end{array}$ & $\begin{array}{l}\text { Geram item escolar até o fim da } \\
\text { condição B. }\end{array}$ \\
\hline
\end{tabular}


entrelaçamento alvo ocorreu com uma taxa acima de $50 \%$, o que pode sugerir o efeito das CCs sobre o responder coordenado das linhagens culturais.

Esses resultados demonstraram que a CC também pode ser efetiva na seleção de CCEs que produzem ganhos mais favoráveis para a cultura, mesmo nas circunstâncias em que tal coordenação compromete a produção de CIs de maior magnitude. Tal dado é compatível com os de outras pesquisas que também avaliaram esse tipo de conflito (cf. Borba, 2013; Magalhães, 2013; Ortu et al., 2012). Esse achado ficou mais evidente na condição $\mathrm{B}$ da $\mathrm{MC} 1$, em que havia sido programado aumento progressivo da CI para as respostas impulsivas e, ainda assim, observou-se mais de $90 \%$ de respostas autocontroladas. No entanto, não foi observada manutenção do entrelaçamento selecionado nessa fase após as mudanças de gerações, semelhante ao que ocorreu na pesquisa de Magalhães (2013).

Em situações de concorrência, como a programada neste estudo, os próprios membros do grupo podem atuar reforçando respostas mais favoráveis à cultura e/ou punindo aquelas respostas que produzem consequências aversivas para o grupo (cf. Borba et al., 2014). Essa punição de respostas impulsivas que comprometem o grupo foi denominada por Borba (2013) de sanções éticas. De acordo com Glenn (1986), a probabilidade de CCs que frequentemente ocorrem a longo prazo atuarem sobre o responder dos indivíduos é muito baixa, de modo que o comportamento verbal torna-se uma ferramenta importante na mediação dessa relação das respostas dos membros do grupo com a consequência comum a longo prazo. Tourinho (2013) também aponta que a eficácia da CC pode depender de sua correlação com consequências sociais de aprovação e desaprovação, mediadas pelos membros do grupo. Os resultados aqui relatados sugerem que aquela correlação pode ser uma variável mais relevante do que a progressão da magnitude da CI concorrente com a CC.

$\mathrm{Na}$ condição $\mathrm{B}$ da $\mathrm{MC1}$, em que houve altas taxas de respostas autocontroladas, um dos participantes, o P8MC1, parece ter atuado liberando sanções éticas quando os outros escolhiam impulsivamente, como pode ser observado nos trechos das interações verbais apresentadas nos resultados. Esse padrão de sanção ética se repetiu no retorno à condição A, quando os participantes P6MC1 e P7MC1 foram substituídos por novos participantes e estes últimos escolheram números ímpares. Nessas ocasiões, o participante P8MC1 comentou: "Percebeu? Você escolheu um número impar e a gente não gerou o item escolar".

Dados sobre ocorrência de autocontrole ético sob arranjos de macrocontingência têm demonstrado que o responder autocontrolado ocorre nas condições em que há possibilidade de interação verbal entre os participantes (Borba et al., 2014). Os dados desta pesquisa sugerem o mesmo resultado sob arranjos de metacontingências, mesmo que a interação verbal não tenha sido uma variável diretamente manipulada nesse estudo. Sugere-se que, em pesquisas futuras, essa variável seja controlada, talvez com a utilização de um confederado especialmente treinado para liberar esse tipo de consequência.

Vale destacar, ainda, que a organização pelo experimentador, sobre a mesa, das fichas que seriam entregues aos participantes pode ter funcionado como uma variável estranha que gerou variabilidade das respostas dos participantes e, consequentemente, menor produção do PA no início da primeira condição A de ambas microculturas. A visualização da pontuação disponível $(1,3,5,10,20$ e 30) no dispositivo em que as fichas estavam distribuídas sobre a mesa de coleta parece ter controlado a resposta dos participantes de buscar uma forma para alcançar as pontuações mais altas, gerando variabilidade, como pode ser observado nos comentários a seguir. O participante $\mathrm{P} 3 \mathrm{MC} 1$ comentou na primeira condição A, no ciclo 50, "São os pares (linhas pares) em sequência crescente ou decrescente pra produzir o item escolar. Tem que saber como faz pra pegar 5, 10, 20 e 30 agora"; no ciclo seguinte, o grupo combinou escolher linhas ímpares, saltando um número, tendo selecionado a sequência 5,9 e 3 . No ciclo 53 , o participante P3MC1 voltou a comentar "Vamos fazer alguma jogada ai pra desbloquear [as pontuações maiores]”. Em seguida, eles voltaram a escolher linhas ímpares, tentaram combinações e todos escolherem o mesmo número e múltiplos.

$\mathrm{Na} \mathrm{MC} 2$, a participante P5MC2, que havia acabado de substituir um participante, questionou aos outros membros do grupo como eles podiam produzir maior pontuação ao que eles responderam afirmando que não sabiam. A participante P5MC2 disse "Então vamos tentar pegar [maior pontuação], gente". A participante $\mathrm{P} 4 \mathrm{MC} 2$ respondeu "Agora eu estou me sentindo desafiada, agora eu quero esse 30 ". Depois disso, os participantes tentaram a sequência 1,5 e 9 ; escolheram números adjacentes 2, 3 e 4; escolheram o mesmo número 7, 7 e 7, entre outras coordenações.

Além de seleção cultural, ao longo de todo o estudo foi observada a seleção operante. Tal seleção foi mais evidente nas condições sem concorrência, em que a produção cultural independia de as respostas individuais serem de escolhas de linhas ímpares ou pares (mas apenas que as linhas fossem de cores diferentes). Foi nessas condições que houve a maior concentração de escolhas de linhas ímpares que produziam maior magnitude de CI, embora houvesse, em todas as condições, independência funcional entre as contingências operantes e culturais programadas, tal como já demonstrado em outros estudos que utilizaram esse mesmo protocolo (Borba, 2013; Soares, et al, 2012).

Outro dado que parece ser compatível com a literatura (Borba, 2013; Soares et al., 2012) é que a segunda exposição à metacontingência parece ser mais eficiente na seleção cultural. Nos resultados das condições em que não havia concorrência, a maior produção de $\mathrm{CC}$ ocorreu no retorno à condição. Para avaliar se esse efeito é produto da história de exposição ou da diferença entre as condições (concorrência e não concorrência) sugere-se uma replicação que utilize um delineamento reverso entre microculturas, conforme realizado em outros estudos da área (e.g., Vichi, Andery, \& Glenn, 2009).

No presente trabalho, pretendeu-se avaliar a manutenção de um dado entrelaçamento por CCs, após processo de seleção por metacontingência, em uma condição de progressão da magnitude da CI concorrente e de natureza diferente da CC. Foi possível constatar que a variação na magnitude da $\mathrm{CI}$ afetou a produção da CC na MC2: na condição sem aumento progressivo da CI, a produção agregada (que dependia de repostas autocontroladas) variava entre $50 \%$ e $60 \%$ nos últimos 50 ciclos; o aumento progressivo da CI (para as 
respostas impulsivas) inserido na condição seguinte resultou na queda da taxa de recorrência do entrelaçamento alvo para $20 \%$. Nessa microcultura, porém, como já assinalado, pode ter desempenhado papel especial a verbalização de um participante, no sentido de que a doação do item à escola independeria da ocorrência do entrelaçamento alvo (uma vez que os itens "já estavam comprados"). Esse evento pode ter contribuído para suspender a efetividade da metacontingência programada. Por outro lado, a mesma condição na MC1 foi a condição em que houve a maior frequência de respostas autocontroladas. Os resultados, portanto, apontam a seleção de CCEs+PAs em condição de concorrência entre metacontingência e contingência operante, sua possível manutenção em condição de aumento progressivo da magnitude da CI concorrente, bem como a variação desse resultado como função de interações verbais intragrupo. Tais resultados requerem estudos adicionais, de modo a aferir a generalidade, bem para como tornar mais evidente os efeitos das variáveis mencionadas.

\section{Referências}

Borba, A. (2013). Efeitos da exposição a macrocontingências e metacontingências na produção e manutenção de respostas de autocontrole ético (Tese de doutorado). Universidade Federal do Pará, Belém, PA, Brasil.

Borba, A., Silva, B. R., Cabral, P. A. dos A., Souza, L. B., Leite, F. L., \& Tourinho, E. Z. (2014). Effects of exposure to macrocontingencies in isolation and social situations in the production of ethical self-control. Behavior and Social Issues, 23, 5-19.

Cavalcanti, D. E., Leite, F. L., \& Tourinho, E. Z. (2014). Seleção de práticas culturais complexas: Avaliação experimental de um análogo do procedimento de aproximação sucessiva. Psicologia e Saber Social, 3(1), 2-21.

Del Prette, Z. A. P., \& Del Prette, A. (2010). Habilidades sociais e análise do comportamento: Proximidade histórica e atualidades. Revista Perspectivas, 1(2), 104-115.

Glenn, S. S. (1986). Metacontingencies in Walden Two. Behavior Analysis and Social Action, 6, 2-8.

Glenn, S. S. (2004). Individual behavior, culture and social change. The Behavior Analyst, 27, 133-151.

Glenn, S. S., \& Malott, M. E. (2004). Complexity and selection: Implications for organizational change. Behavior and Social Issues, 13, 89-106.

Magalhães, F. G. (2013). Efeitos da incompatibilidade entre consequências individuais e culturais em análogos experimentais de metacontingências (Tese de doutorado). Pontifícia Universidade Católica de São Paulo, São Paulo, SP, Brasil.

Malott, M. E., \& Glenn, S. S. (2006). Targets of intervention in cultural and behavioral change. Behavior and Social Issues, $15,31-56$.

Ortu, D., Becker, A. M., Woelz, T. A. R., \& Glenn, S. S. (2012). An iterated four-player Prisoner's Dilemma Game with an external selecting agent: A metacontingency experiment. Revista Latinoamericana de Psicología, 44, 111-120.
Pavanelli, S., Leite, F. L., \& Tourinho, E. Z. (2014). A “modelagem” de contingências comportamentais entrelaçadas complexas. Acta Comportamentalia, 22(4), 425-440.

Soares, P. F. R., Cabral, P. A. A., Leite, F. L., \& Tourinho, E. Z. (2012). Efeitos de consequências culturais sobre a seleção e manutenção de duas práticas culturais alternadas. Revista Brasileira de Análise do Comportamento, 8(1), 37-46.

Tourinho, E. Z. (2006). Mundo interno e autocontrole. Revista Brasileira de Análise do Comportamento, 2(1), 21-36.

Tourinho, E. Z., \& Vichi, C. (2012). Behavioral-analytic research of cultural selection and the complexity of cultural phenomena. Revista Latinoamericana de Psicologia, 44, 169-179.

Tourinho, E. Z. (2013, Novembro). Consequências culturais selecionam contingências comportamentais entrelaçadas? Comentário sobre características da seleção no nível cultural. Trabalho apresentado no I Simpósio Amazônico Sobre Teoria e Pesquisa do Comportamento, Belém, PA.

Vichi, C., Andery, M. A. P. A. \& Glenn, S. S. (2009). A metacontingency experiment: The effects of contingent consequences on patterns of interlocking contingencies of reinforcement. Behavior and Social Issues, 18, 41-57.

Recebido em 16.09.2015

Primeira decisão editorial em 08.06.2016

Versão final em 04.07.2016

Aceito em 18.07.2016 